\title{
ESCOLARIZAÇÃO ABERTA COM MAPAS DE INVESTIGAÇÃO NA EDUCAÇÃO EM REDE: apoiando a Pesquisa e Inovação Responsáveis (RRI) e a diversão na aprendizagem
}

\author{
Alexandra Okadal \\ Luziana Quadros da Rosa² \\ Márcio Vieira de Souza 3
}

\begin{abstract}
RESUMO
Este artigo discute a Escolarização Aberta que é uma abordagem promovida pela Comissão Europeia para preparar os estudantes em cooperação com parceiros para desenvolver projetos sobre questões do mundo real e construir juntos um futuro desejável. Essa abordagem foi projetada para envolver todos os participantes na RRI - Pesquisa e Inovação Responsáveis (EC, 2015). O objetivo da RRI é alinhar pesquisa e inovação com as necessidades da sociedade e com os objetivos de desenvolvimento sustentável (UNESCO, 2015) por meio da interação de pesquisadores com cidadãos. A Escolarização Aberta para a RRI é considerada uma abordagem interativa para ajudar os jovens a desenvolver conhecimentos, habilidades, atitudes e valores para o século 21. Este estudo apresenta algumas contribuições quanto ao uso de mapas de investigação (OKADA, 2006) como método participativo de pesquisa-ação para envolver múltiplos parceiros em uma rede aberta. Este estudo exploratório, apoiado por um conjunto de exemplos da literatura, fornece recomendações para o desenvolvimento de mapas de investigação para projetos de Escolarização Aberta em rede e facilita a diversão na aprendizagem.
\end{abstract}

Palavras-chave: Escolarização aberta. Mapas de investigação. Pesquisa e inovação responsáveis. Educação em rede. Diversão e aprendizagem.

\section{OPEN SCHOOLING WITH INQUIRY MAPS IN NETWORK EDUCATION:}

\section{supporting Responsible Research and Innovation (RRI) and fun in learning}

\footnotetext{
${ }^{1}$ Doutora em Educação. Pesquisadora Sênior da Academia de Ensino Superior do Reino Unido (UK), Pesquisadora Educacional da Faculdade de Bem-Estar, Educação e Estudos da Linguagem - The Open University, Milton Keynes, Reino Unido. Orcid ID: http://orcid.org/00000003-1572-5605, E-mail: alexandra.okada@gmail.com.

2 Mestra em Tecnologias da Informação e Comunicação. Doutoranda pela Universidade Federal de Santa Catarina no Programa de Pós-Graduação em Engenharia e Gestão do Conhecimento, Florianópolis - SC, Brasil. Orcid ID: http://orcid.org/0000-0002-5689-4184. Email: cpead.bpi.luziana@gmail.com.

3 Doutor em Engenharia de Produção. Professor no Programa de Pós-Graduação em Engenharia e Gestão do Conhecimento da Universidade Federal de Santa Catarina, Florianópolis - SC, Brasil. Orcid ID: http://orcid.org/0000-0002-0165-4036. E-mail: marciovieiradesouza@gmail.com
} 


\begin{abstract}
This article discusses the open schooling approach which has been promoted by the European Commission for preparing learners in cooperation with partners to develop real-world issue projects and shape a desirable future together. This approach is designed to engage all participants with RRI - Responsible Research and Innovation (EC, 2015). The objective of RRI is to align research and innovation with societal needs and sustainable development goals (UNESCO, 2015) through the interaction of researchers with society. Open schooling for RRI is considered an interactive approach to help youth develop knowledge, skills, attitude and values for the 21 st century. This study presents some contributions of using inquiry mapping (OKADA, 2006) as a participatory research-action method to engage multi-partners in an open network. This exploratory study supported by a set of examples from the literature provides recommendations for developing inquiry-maps for open schooling in network projects and facilitates fun in learning.
\end{abstract}

Keywords: Open schooling. Inquiry maps. Responsible Research and Innovation. Network education. Fun and learning.

\title{
ESCOLARIDAD ABIERTA CON MAPAS DE INVESTIGACIÓN EN EDUCACIÓN EN RED: en apoyo de la Investigación y Innovación Responsables (RRI) y la diversión en la aprendizaje
}

\section{RESUMEN}

Este artículo aborda el enfoque de la escolaridad abierta que fue promovido por la Comisión Europea para preparar a los estudiantes en cooperación con socios para desarrollar proyectos sobre problemas del mundo real y construir juntos un futuro deseable. Este enfoque fue diseñado para involucrar a todos los participantes en RRI - Investigación e innovación responsables (EC, 2015). El objetivo de RRI es alinear la investigación y la innovación con las necesidades de la sociedad y con los objetivos del desarrollo sostenible (UNESCO, 2015) a través de la interacción de los investigadores con los ciudadanos. La escolaridad abierta para RRI se considera un enfoque interactivo para ayudar a los jóvenes a desarrollar conocimientos, habilidades, actitudes y valores para el siglo 21. Este estudio presenta algunas contribuciones del uso de mapas de investigación (OKADA, 2006) como un método de investigación de acción participativa para involucrar a múltiples socios en una red abierta. Este estudio exploratorio, respaldado por un conjunto de ejemplos de la literatura, proporciona recomendaciones para el desarrollo de mapas de investigación para proyectos de la escolaridad abierta en red y facilita la diversión en el aprendizaje.

Palabras clave: Escolaridad abierta. Mapas de investigación; Investigación e innovación responsables. Educación en red. Divertido y aprendizaje.

\section{INTRODUÇÃO: EDUCAÇÃO EM REDE}

O mundo contemporâneo dominado pela ciência e tecnologia requer uma sociedade em rede cientificamente informada (CASTELLS, 2010) com

Revista Exitus, Santarém/PA, Vol. 10, p. 01-36, e020054, 2020. 
estudantes e educadores, em rede, cientificamente alfabetizados (EC, 2015). A educação em rede, com as novas abordagens pedagógicas, é necessária para equipar as gerações de cidadãos responsáveis e pesquisadores inovadores. Essa geração deve estar preparada para enfrentar desafios locais e globais, incluindo questões sociocientíficas conhecidas e desconhecidas, cada vez mais complexas, e compactadas no espaço e no tempo, interconectadas e sem fronteiras (HOLST 2006; BRYDON, 2011) que afetam nossa vida na Terra, por exemplo, como as questões de aquecimento global, destruição ambiental e novas doenças pandêmicas como a COVID-19.

A educação em rede, que faz parte da sociedade em rede (CASTELLS, 2010), tem um "desafio macro" de promover a aprendizagem interconectada que integra currículo formal, recursos educacionais não formais e contextos informais com cenários locais globais; incluindo questões da vida real, dados atualizados e conhecimentos recentes, além de ambientes digitais, não digitais e híbridos (OKADA; RODRIGUES, 2018).

A educação em rede envolve uma sociedade em rede interconectada com as ciências em rede (ROSA et al., 2018; SOUZA, 2015). E torna-se cada vez mais relevante para a construção de uma educação mais interativa, interconectada, inclusiva e inovadora, alinhada às necessidades, prioridades e expectativas das sociedades em rede por um mundo sustentável. Esse alinhamento da ciência com e para a sociedade é o significado principal de Responsible Research and Innovation - RRI (EC, 2015). Desse modo, para que os estudantes possam contribuir para esse alinhamento, surgiu à nova abordagem da Escolarização Aberta (EC, 2015) para promover a cooperação entre escolas, universidades e empresas para as áreas de STEM - Science, Technology, Engineering \& Mathematics. Para estabelecer uma Escolarização Aberta, os parceiros trazem cenários da vida atual e oportunidades para os estudantes em rede aprenderem com atores sociais distintos, por exemplo, com pesquisadores, profissionais e membros da comunidade. 
Um dos principais desafios da Escolarização Aberta é promover cidadãos com conhecimento científico e aumentar os interesses dos jovens em carreiras científicas, pesquisa e inovação (RYAN, 2015; EC, 2015). A Escolarização Aberta é uma abordagem introduzida pela Comissão Europeia para promover o ensino de ciências para uma cidadania responsável (RYAN, 2015). Seu objetivo é apoiar as escolas a prepararem os estudantes como participantes ativos em projetos autênticos em cooperação com especialistas, pesquisadores, famílias, educadores e comunidades locais para juntos formar um futuro melhor. A Escolarização Aberta é projetada para integrar a aprendizagem formal e informal usando métodos centrados nos estudantes, tais como projetos baseados na aprendizagem, comunidade, resolução de problemas e de pesquisa-ação participativa, considerando as questões importantes do mundo. Seu objetivo é capacitar todos os estudantes a desenvolver conhecimentos, habilidades e atitudes relevantes.

Este artigo argumenta que teorias, metodologias, tecnologias e parcerias em rede, na educação, devem ser usadas no desenvolvimento de abordagens significativas para o aprendizado e ensino em redes, apoiadas pelo pensamento em rede. O pensamento em rede é um processo cognitivo suportado por conceitos e métodos da ciência em rede, sendo importante para o aluno identificar problemas e buscar conhecimentos e soluções relevantes. O pensamento em rede (OKADA, 2008) permite que os estudantes explorem uma questão sociocientífica "descrevendo suas partes constituintes (neste caso, as redes), elaborando essas partes de múltiplas perspectivas e chegando a um todo mais abrangente" (FERGUSON, 2019, p. 7).

Este artigo considera que a Escolarização Aberta sustentada pela educação em rede para o RRI exige educar os estudantes com capital científico interconectado (ARCHER et al., 2015), que integra conhecimento, habilidades, atitudes, valores e parcerias. O capital científico e a alfabetização científica em (inter)ação são vitais para os estudantes juntamente com parceiros sociais possam moldar um futuro desejável. Para 
que essas interconexões e interações ocorram, a educação em rede com a Escolarização Aberta também têm um "micro desafio" que é de preparar os estudantes de maneira mais holística, com habilidades cognitivas e não cognitivas, incluindo as soft e hard skills para que eles possam interagir, cooperar e aprender juntamente com parceiros distintos. A cooperação entre atores distintos exige que os estudantes
adquiram linguagem conceitual, habilidades de raciocínio e
abordagens participativas divertidas que os ajudarão a interagir com
especialistas e comunidades da sociedade civil e, assim, aprender
de maneira mais significativa e agradável. O conhecimento, as
competências e o pensamento interconectado dos estudantes, que
incluem diversão profunda para um aprendizado mais profundo, são
necessários para permitir que eles co-criem ações de forma
responsável e com engajamento intrínseco para que eles realizem,
explorem, compreendam e moldem os seus conhecimentos em
rede, em direção a um futuro desejável e de forma colaborativa.
(OKADA, 2020, p. 3).

A principal contribuição deste artigo é fornecer um método de "mapeamento de investigação" para apoiar o pensamento em rede com exemplos de princípios e práticas, fundamentados em estudos anteriores (RAMOS et AL., 2019; ROCHA et. AL., 2018; OKADA, 2014;), e, analisados sob as novas lentes da Escolarização Aberta em rede; em particular, para ser usado no contexto da educação em rede para RRI (CE, 2015) e apoiar aprendizagem divertida. A diversão profunda refere-se à motivação intrínseca para realização plena, na qual os alunos estão profundamente envolvidos com alegria de aprender e alcançar desafios e objetivos cada vez maiores para autotransformação (OKADA, 2020).

O artigo foca o pensamento em rede praticado por estudantes com aprendizagem baseada em investigação (OKADA, 2008; OKADA, 2010) para aprimorar um conjunto de habilidades de aprendizagem, que são baseadas em investigação para a RRI: elaborar perguntas de pesquisa, interrogar fontes, usar ética, analisar dados, tirar conclusões, examinar consequências, estimar riscos, criticar afirmações, justificar opiniões e comunicar resultados; usando tecnologias digitais participativas (OKADA; SHERBORNE, 2018). 


\section{PENSAMENTO EM REDE COM MAPEAMENTO DE INVESTIGAÇÃO}

Para facilitar a Escolarização Aberta, o método de mapeamento de investigação pode ser usado por estudantes apoiados por professores e outros parceiros para identificar, examinar e resolver desafios que afetam indivíduos, comunidades e o planeta.

O Mapeamento de investigação visa orientar as comunidades de aprendizagem a encontrar questões sociocientíficas relevantes apoiadas por parceiros e suas fontes recomendadas, tudo em rede. Este método consiste em três fases cíclicas com espaços interconectados, veja a Figura 1, (OKADA, 2010).

FIGURA 1 - Mapeamento de investigação

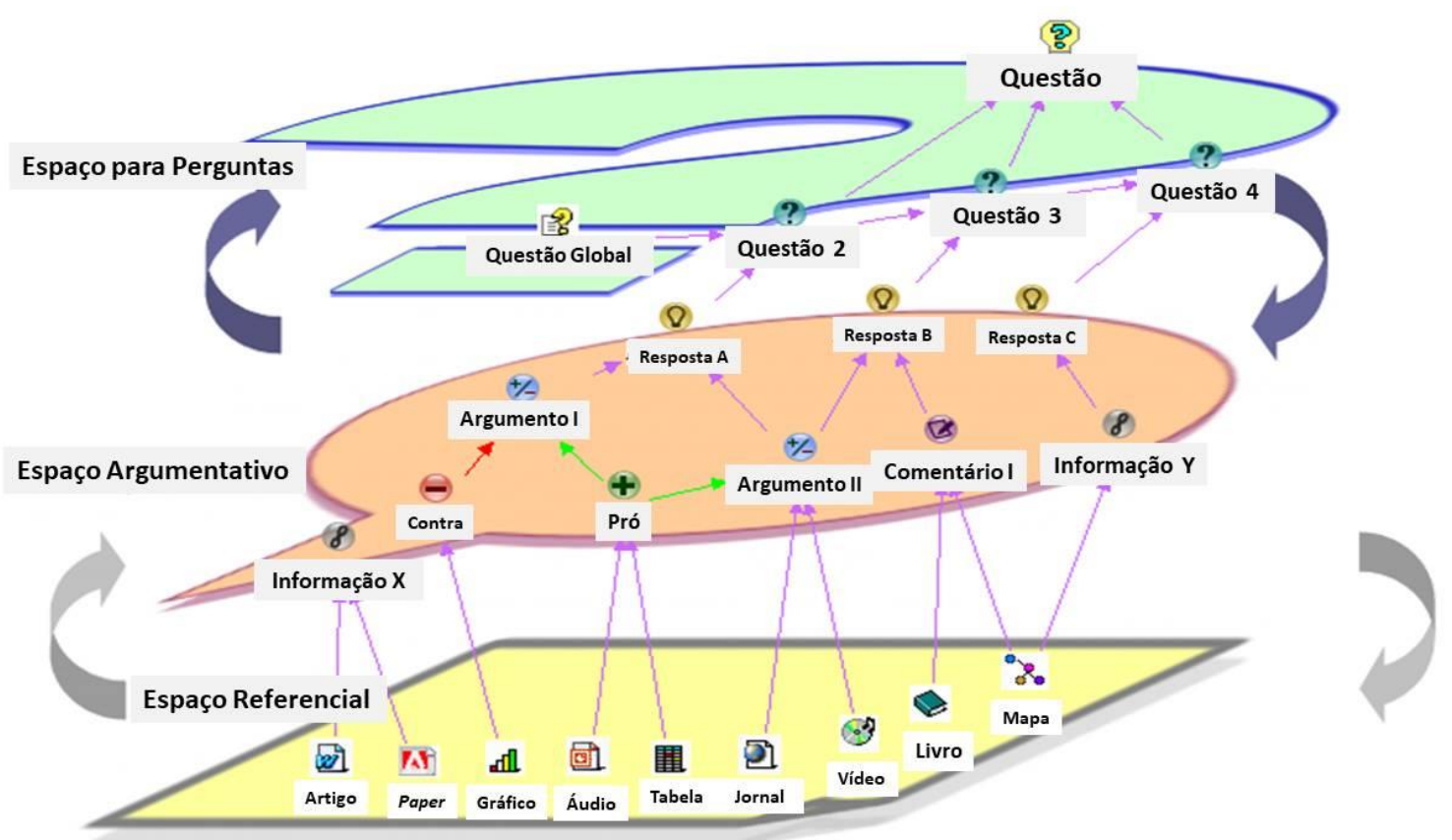

Fonte: Okada, 2010. Software tool: Compendium.

1. O espaço referencial inclui uma rede de escritores e seus documentos e referências científicas, ciência nas notícias, repositórios acadêmicos e informações na mídia. Essa rede permite que os facilitadores criem perguntas globais para iniciar a segunda fase.

2. O espaço argumentativo inclui uma rede de representantes da comunidade e suas visões argumentativas sobre questões globais. Essa rede permite a criação de perguntas locais para iniciar a terceira fase. 
3. O espaço para perguntas inclui uma rede de perguntas temáticas para que os membros da comunidade selecionem, ampliem ou adicionem novas questões, em colaboração com parceiros para apoiar projetos de ação participativa com os membros da comunidade e / ou pesquisa participativa informada.

Pensamento em rede através do mapeamento de investigação visa ajudar os participantes a identificar, conectar e interpretar questões, ideias, conceitos, dados e argumentos importantes de suas práticas e fontes de pesquisa por meio de sugestões fornecidas por todos os parceiros, com o apoio de pesquisadores, colegas e educadores facilitadores. O mapeamento de investigação baseia-se no trabalho de Jonassen (2000), que definiu alguns princípios para promover três conjuntos de habilidades de pensamento (OKADA, 2010):

- O pensamento básico do conteúdo representa a capacidade de entender as informações aceitas, o conhecimento declarativo e explícito. Refere-se à habilidade de interpretar conhecimentos gerais e informações de senso comum. O pensamento básico do conteúdo requer aprender e recuperar o que foi aprendido.

- O pensamento crítico representa o processo dinâmico de mapear o conhecimento de maneiras significativas e úteis através da análise, avaliação e conexões. Ele integra habilidades importantes, como avaliar o processo por critérios apropriados, analisando as interrelações entre os elementos relevantes mapeados por meio de conexões e reconhecendo lacunas, imprecisões e equívocos.

- O pensamento criativo mostra a capacidade de ir além do conhecimento aceito para criar novas questões e reconstruir novos conhecimentos. O pensamento criativo deve estar conectado ao pensamento de conteúdo e ao pensamento crítico, a fim de integrar o conhecimento existente com a habilidade do pensamento inovador. 


\section{Princípios de Mapeamento de investigação}

O método de mapeamento de investigação, denominado em inglês como inquiry mapping - e que também pode ser compreendido, em uma tradução literal em português, como método de mapeamento de pesquisa ou problema científico - é apoiado pela aprendizagem baseada em perguntas, que se tornou uma abordagem importante para envolver os estudantes em projetos de investigação. Seu principal objetivo é ajudar os estudantes a agirem como pensadores críticos para gerenciar sua própria investigação, em vez de agirem como receptores passivos de conteúdo.

Freire (1967) destaca que o pensamento crítico é uma habilidade importante não apenas para apreender o significado, o conhecimento e a verdade da realidade, mas também para tomar decisões, implementar ações e melhorar os resultados, provocando mudanças e possibilitando transformações. Para ser crítico, é necessário pensar-agir-refletir visando melhorias (práxis). Também, envolve ler e escrever o mundo - não apenas identificando palavras, mas também entendendo seus significados, razões, consequências, objetivos, contexto, referências e evidências.

A aprendizagem baseada em investigação é considerada um processo complexo. Os professores como facilitadores da pesquisa precisam fornecer aos estudantes estratégias, ferramentas e orientações, ajudando-os a aplicar o que sabem ou o que estão aprendendo no processo de pesquisa e solução problemas (EDELSON, 2001; HMELO-SILVER; DUNCAN; CHINN, 2007). A aprendizagem baseada em investigação exige que os estudantes desenvolvam várias habilidades.

Para construir conhecimento durante a sua investigação, os estudantes devem ser capazes de:

1. Formular perguntas-chave.

2. Selecionar as informações relevantes para solucionar os principais problemas.

3. Identificar novos conhecimentos que façam sentido para construir significados. 
4. Escolher métodos apropriados para análise da investigação.

5. Desenvolver possíveis soluções e tirar conclusões.

6. Obter feedback e pontos de vista para avaliar o processo e os resultados.

As abordagens de pesquisa participativa também são enquadradas como um processo contínuo e colaborativo de levantar questões significativas, integrar informações relevantes e gerar linhas de raciocínio aceitáveis, baseadas em suposições científicas e corpos de conhecimento (VEERMAN, 2003). O mapeamento de investigação é uma abordagem metodológica para facilitar a pesquisa-ação participativa. É baseado em seis técnicas de mapeamento descritas no quadro a seguir (Quadro 1).

QUADRO 1 - Mapa gêneros de conhecimento - Cartografia do Conhecimento

\begin{tabular}{|c|c|c|}
\hline $\begin{array}{c}\text { Técnicas de Mapeamento } \\
\text { Concept Mappings } \\
\text { (NOVAK, 1998) }\end{array}$ & Objetivos & Recursos Gratuitos \\
\hline $\begin{array}{c}\text { Mind Mapping } \\
\text { (BUZAN, 1993) }\end{array}$ & Gerar ideias & MindMeister \\
\hline $\begin{array}{c}\text { WebMapping } \\
\text { (OKADA; ZEILIGER, 2003) }\end{array}$ & Coletar recursos da Web & Lucidchart \\
\hline $\begin{array}{c}\text { ISsue Mapping } \\
\text { (CONKLIN, 2005) }\end{array}$ & Estruturar discussões & Compendium \\
\hline $\begin{array}{c}\text { Argument Mapping } \\
\text { (GELDER, 2002) }\end{array}$ & Desenvolver argumentação & LiteMap \\
\hline $\begin{array}{c}\text { Evidence-based dialogue } \\
\text { mapping (OKADA, 2008) }\end{array}$ & $\begin{array}{c}\text { Desenvolver o pensamento } \\
\text { crítico }\end{array}$ & $\begin{array}{c}\text { Compendium } \\
\text { LiteMap }\end{array}$ \\
\hline
\end{tabular}

Fonte: Atualizado de Okada, 2014.

O mapeamento do conhecimento para projetos de investigação visa ajudar os usuários a mediar o processo de abstração, em sua concepção latina "abstractere", que significa "retirá-lo" do mundo externo, para concretizá-lo e devolvê-lo ao mundo mapeado, interpretado e modificado pelo pensamento crítico (OKADA, 2006). A interpretação do conhecimento a partir de mapas também apoiam os estudantes a visualizar e identificar estruturas ou etapas importantes em torno do formato da solução de problemas, tais como: generalizações, enumerações, sequência, classificação e comparação e contraste (COOK; MAYER, 1988). 
Os mapas de investigação podem ser aplicados em várias etapas de um projeto de pesquisa para tornar o pensamento visível, desenhando componentes e linhas de raciocínio. Essas vias de investigação fornecem orientação representacional aos pesquisadores para interpretar e construir significados, visualizando os principais componentes e suas conexões. Mc Tighe (1992, p. 183) também aponta que as representações gráficas

provaram ser ferramentas eficazes para aumentar 0 pensamento e promover a aprendizagem significativa, ajudando professores e alunos a organizarem a informação, gerar muitas ideias, representar conceitos abstratos, ilustrar as relações, relacionar novas informações com conhecimento prévio, armazenar e recuperar informações e avaliar o pensamento e o aprendizado.

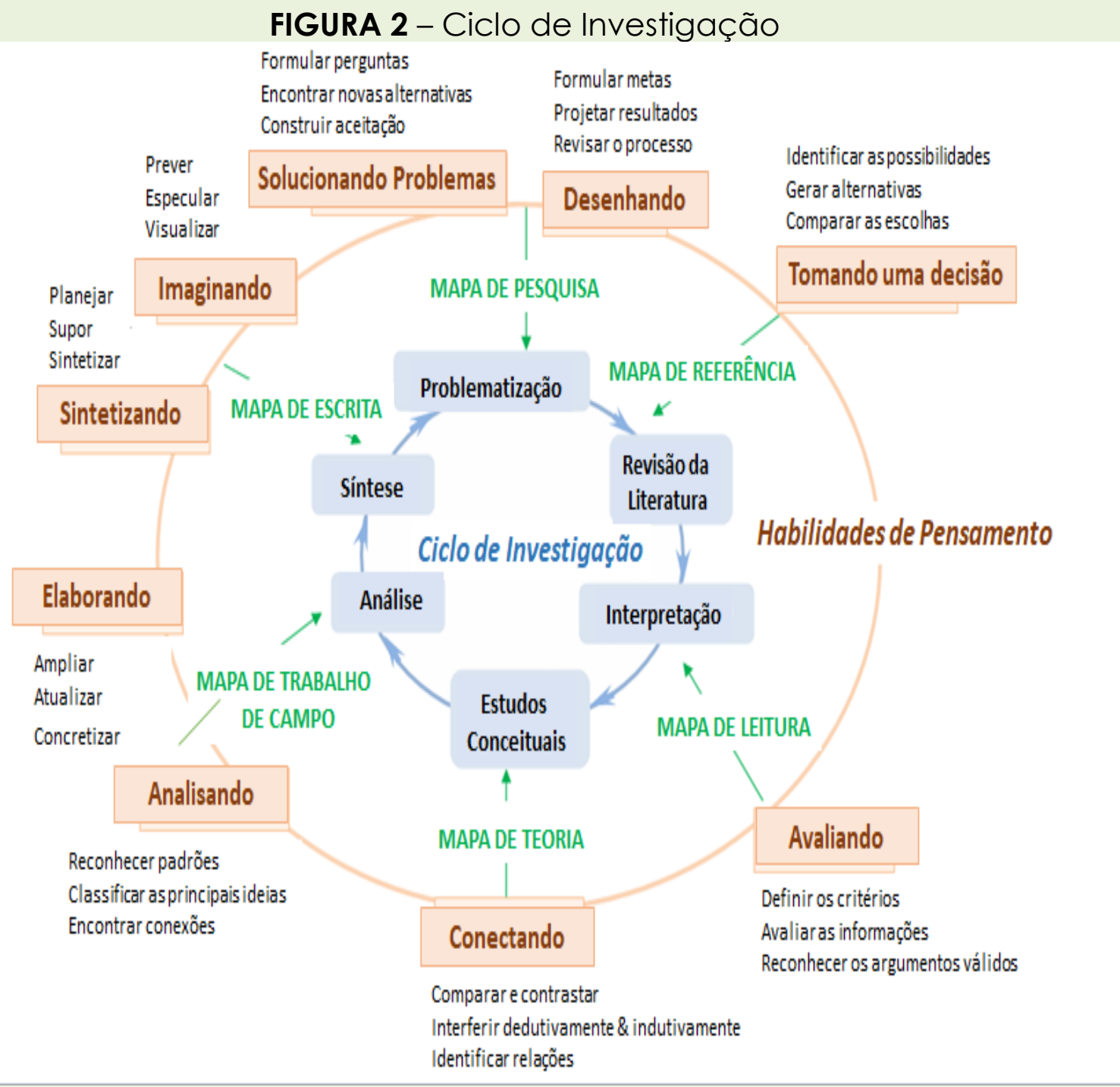

Fonte: Okada, 2010. Ferramenta de software: Word.

Revista Exitus, Santarém/PA, Vol. 10, p. 01-36, e020054, 2020. 
A Figura 2 descreve seis tipos de mapas de pesquisa (OKADA, 2006) que podem ser usados para desenvolver seis estágios de um projeto de Escolarização Aberta apoiado pelo pensamento em rede (JONASSEN, 2000).

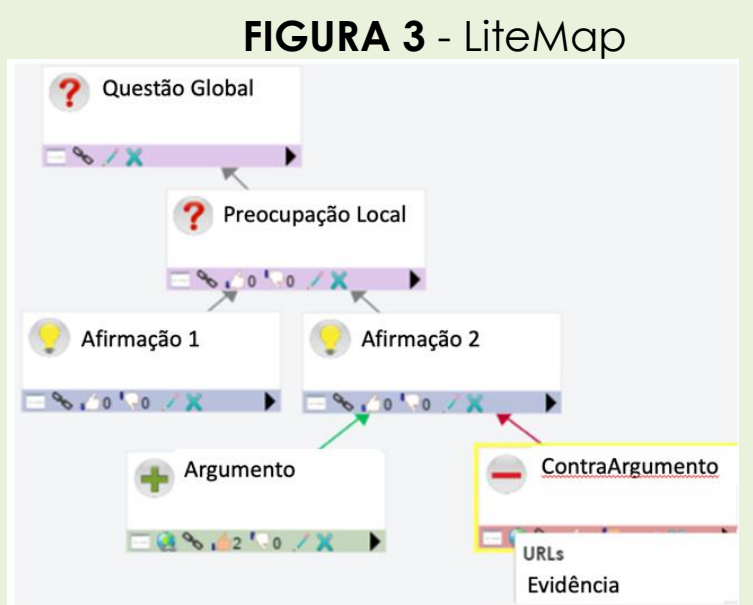

Fonte: Okada, 2010. Ferramenta de software: Word

A Figura 3 descreve os principais componentes do mapeamento de diálogo com base em evidências. Os estudantes juntamente com os parceiros mapeiam questões globais e preocupações locais, conectam ideias (depoimentos). Em seguida, eles conectam argumentos de apoio e contra argumentos que estão linkados às evidências. O mapa permite que os participantes visualizem perguntas que não têm respostas, respostas que não estão conectadas aos argumentos e argumentos que não têm evidências.

Para apresentar os benefícios do uso do mapeamento de investigação, no desenvolvimento de habilidades de pensamento em rede em projetos de pesquisa, selecionamos alguns princípios (JONASSEN, 2000) para analisar os seis modelos de mapas (Quadro 2): mapa de pesquisa, mapa de referência, mapa de leitura, mapa de teoria, mapa de trabalho de campo e mapa de escrita.

QUADRO 2 - Eliciação de habilidades de pensamento através de mapas de investigação

\begin{tabular}{|l|l|ll|}
\hline $\begin{array}{l}\text { Mapas de } \\
\text { investigação }\end{array}$ & $\begin{array}{l}\text { Habilidades de } \\
\text { pensamento }\end{array}$ & Etapas da pesquisa & \\
$\begin{array}{l}\text { Mapa de } \\
\text { pesquisa }\end{array}$ & $\begin{array}{l}\text { Projetar a } \\
\text { solução de }\end{array}$ & $\begin{array}{l}\text { Problematização: mapeie um brainstorm de de } \\
\text { perguntas para encontrar os principais problemas. }\end{array}$ \\
\hline
\end{tabular}




\begin{tabular}{|c|c|c|}
\hline & problemas & \\
\hline $\begin{array}{l}\text { Mapa de } \\
\text { referência }\end{array}$ & $\begin{array}{l}\text { Tomar uma } \\
\text { decisão }\end{array}$ & $\begin{array}{l}\text { Revisão de literatura: mapeie fontes de referência } \\
\text { relevantes para selecionar a literatura chave para } \\
\text { fundamentar suas ideias. }\end{array}$ \\
\hline $\begin{array}{l}\text { Mapa } \\
\text { leitura }\end{array}$ & Avaliar & $\begin{array}{l}\text { Interpretação: mapeie o conteúdo dos trabalhos } \\
\text { selecionados para entender os principais conceitos. }\end{array}$ \\
\hline $\begin{array}{l}\text { Mapa } \\
\text { teoria }\end{array}$ & Conectar & $\begin{array}{l}\text { Estudos conceituais: mapear diferentes abordagens } \\
\text { para integrar um corpo-chave de conhecimento. }\end{array}$ \\
\hline $\begin{array}{l}\text { Mapa } \\
\text { trabalho } \\
\text { campo }\end{array}$ & $\begin{array}{l}\text { Elaborar } \\
\text { análises }\end{array}$ & $\begin{array}{l}\text { Análise: mapeie seus dados com base em um } \\
\text { método de consulta apropriado para abordar as } \\
\text { questões de pesquisa. }\end{array}$ \\
\hline $\begin{array}{l}\text { Mapa } \\
\text { escrita }\end{array}$ & $\begin{array}{l}\text { Sintetizar a } \\
\text { imaginação }\end{array}$ & $\begin{array}{l}\text { Síntese: mapear os principais componentes do } \\
\text { processo de pesquisa: questões, referências, } \\
\text { conceitos, métodos, dados e descobertas, a fim de } \\
\text { visualizar os principais argumentos e desenvolver um } \\
\text { resumo coerente. }\end{array}$ \\
\hline
\end{tabular}

Fonte: Okada, 2010.

A literatura sobre Escolarização Aberta é limitada, pois é um conceito recente. Estudos anteriores sobre Escolarização Aberta sugerem que um desafio fundamental é apoiar as comunidades com métodos participativos e práticos para envolver todos os múltiplos atores: escolas, universidades, empresas, sociedade civil e os agentes e/ ou formuladores de políticas públicas; permitindo que possam desenvolver juntos projetos sobre questões do mundo real (OKADA; SHERBORNE, 2018). Para explorar essa lacuna, este estudo exploratório utilizou o método de mapeamento de investigação, que foi projetado para apoiar a pesquisa colaborativa facilitada pelo método de pensamento em rede, denominado de método de 'mapeamento de investigação' (OKADA, 2008), aplicado por estudantes juntamente com parceiros e utilizando várias ferramentas.

As principais questões de pesquisa deste estudo são:

RQ1. De que maneira o método de mapeamento de investigação permite a cooperação entre estudantes, professores e profissionais de STEM e / ou sua comunidade?

RQ2. De que maneira os mapas de investigação apoiam os estudantes com o pensamento em rede?

Para responder a essas perguntas, este estudo apresenta a abordagem de mapeamento da investigação, seus fundamentos, exemplos 
analisados e apoiados por um estudo qualitativo que fornece algumas recomendações para promover projetos de Escolarização Aberta em rede.

\section{METODOLOGIA}

Este estudo exploratório foi apoiado por RRI, dados abertos e instrumentos participativos de acesso aberto.

Este estudo se concentrou nas comunidades de Escolarização Aberta do projeto ENGAGE, que foi financiado pela Comissão Europeia para aprimorar o ensino de ciências e aumentar a conscientização sobre o RRI com a aprendizagem baseada em investigação, por meio de parcerias entre escolas, universidades e comunidade local.

A plataforma ENGAGE, múltiplos idiomas e multi-ator, disponibiliza um conjunto de tarefas introdutórias (lições); atividades divertidas e práticas (duas aulas); e, projetos com cenários de Escolarização Aberta agrupados em seis categorias: saúde (bem-estar), meio ambiente, transporte, energia, tecnologias, ciência e sociedade. Cada cenário incluiu Recursos Educacionais Abertos (REA) para educadores, estudantes e parceiros desenvolverem projetos liderados por estudantes. Além disso, a plataforma forneceu um sistema de parceria de mediação para as escolas interagirem com profissionais da área de STEM de universidades e com a comunidade local.

Um conjunto de ferramentas participativas reflexivas e divertidas para planejamento, desenvolvimento e autoavaliação de projetos de Escolarização Aberta, também estava disponível na plataforma, para apoiar o pensamento em rede e as dez habilidades de investigação para o RRI (OKADA; SHERBORNE, 2018).

Essas ferramentas participativas-reflexivas apresentam dinâmicas de grupo, para pensar e falar sobre modelos de consequências e análise de risco; cartões e tabuleiro de gamificação, para aplicativos de mapas de tomada de decisão e consulta com tutoriais e guia de autoavaliação. Além disso, a plataforma oferece para cada cenário de Escolarização Aberta 
uma área para professores de ciências adicionarem comentários e exemplos de projetos liderados por estudantes, desenvolvidos em vários formatos, mídias e ferramentas; por exemplo, com entrevistas com pesquisadores, blog de relatórios científicos, infográfico em formato de pôster, vídeo de webinar, mapa de dados e anotação do mapa.

Para responder às perguntas da pesquisa, examinando as melhores práticas (que foram obtidas como dados de fontes secundárias), os autores que representam grupos e campos distintos usaram o guia de mapeamento de autoavaliação, que oferece um conjunto de critérios: princípios de eliciação, rubricas de mapas de investigação e características estéticas (OKADA, 2010).

Os princípios de eliciação permitem que as equipes avaliem o pensamento em rede, representado no mapa de investigação, através de seis componentes para verificar quando os resultados do projeto contêm:

(E)xplicit goals (objetivos explícitos) - objetivos claros, por exemplo, com perguntas ou problemas.

(L)earning actions (ações de aprendizagem) - etapas usadas no desenvolvimento do develop projeto de investigação.

(I)nteresting information (informações interessante) - conceitos relevantes, dados, referências.

(C)lear connections (conexões claras) - links coerentes, linhas explícitas de raciocínio.

(I)ntegrated overview (visão global integrada) - resumo organizado, imagem clara e grande.

(T)rail signed route (trilha com rota sinalizada) - marcas visuais, caminhos rastreados fáceis de seguir.

As rubricas de mapeamento de investigação (Quadro 3) permitem que as equipes avaliem os componentes. Cada rubrica contém uma pergunta para avaliar a relevância.

QUADRO 3 - Eliciação de habilidades de pensamento por meio de rubrica de mapas de investigação. 


\begin{tabular}{|c|c|c|}
\hline $\begin{array}{l}\text { Mapas de } \\
\text { Investigação }\end{array}$ & Rubricas & $\begin{array}{l}\text { Algumas perguntas para avaliar componentes de } \\
\text { mapas de investigação }\end{array}$ \\
\hline \multirow[t]{3}{*}{$\begin{array}{l}\text { Mapa de } \\
\text { pesquisa }\end{array}$} & $\begin{array}{l}\text { Pesquisa- } \\
\text { Questões }\end{array}$ & $\begin{array}{l}\text { - O seu mapa apresenta boas perguntas ou objetivos } \\
\text { de pesquisa? }\end{array}$ \\
\hline & $\begin{array}{l}\text { Pesquisa- } \\
\text { Descrição }\end{array}$ & $\begin{array}{l}\text { - O seu projeto de pesquisa é bem descrito através de } \\
\text { perguntas-chave: O quê? Por quê? Para quê? Quem? } \\
\text { Onde? Quão? Quando? }\end{array}$ \\
\hline & $\begin{array}{l}\text { Pesquisa- } \\
\text { Conhecimento }\end{array}$ & - Seu conhecimento prévio sobre o tema é visível? \\
\hline \multirow[t]{3}{*}{$\begin{array}{ll}\text { Mapa } & \text { de } \\
\text { referência }\end{array}$} & $\begin{array}{l}\text { Referência- } \\
\text { Relevância }\end{array}$ & $\begin{array}{l}\text { - O seu mapa indica referências relevantes no campo } \\
\text { de pesquisa? }\end{array}$ \\
\hline & $\begin{array}{l}\text { Referência- } \\
\text { Quantidade }\end{array}$ & $\begin{array}{l}\text { - Seu mapa mostra referências suficientes para iniciar } \\
\text { seu estudo? }\end{array}$ \\
\hline & $\begin{array}{l}\text { Referência- } \\
\text { Estrutura }\end{array}$ & $\begin{array}{l}\text { - Suas referências estão bem organizadas por } \\
\text { conceitos-chave? }\end{array}$ \\
\hline \multirow[t]{3}{*}{ Mapa de leitura } & $\begin{array}{l}\text { Leitura- } \\
\text { Síntese }\end{array}$ & - O seu mapa mostra um bom resumo do seu texto? \\
\hline & $\begin{array}{l}\text { Leitura- } \\
\text { Categorias }\end{array}$ & $\begin{array}{l}\text { - Os conceitos-chave para estruturar sua leitura estão } \\
\text { bem descritos? } \\
\text { (tema, relevância, objetivos, conceitos, análises } \\
\text { afirmações, evidências, conclusões). }\end{array}$ \\
\hline & $\begin{array}{l}\text { Leitura- } \\
\text { Compreensão }\end{array}$ & - Seu mapa permite que você entenda o conteúdo? \\
\hline \multirow[t]{3}{*}{ Mapa de teoria } & $\begin{array}{l}\text { Teoria } \\
\text {-Relevância }\end{array}$ & - O seu mapa apresenta uma teoria relevante?? \\
\hline & $\begin{array}{l}\text { Teoria- } \\
\text { Pontos de vista }\end{array}$ & - Seu mapa integra diferentes pontos de vista? \\
\hline & $\begin{array}{l}\text { Teoria- } \\
\text { Significados }\end{array}$ & - Seu mapa permite visualizar novos significados? \\
\hline \multirow{3}{*}{$\begin{array}{l}\text { Mapa } \\
\text { trabalho } \\
\text { campo }\end{array}$} & $\begin{array}{l}\text { Dados- } \\
\text { Relevância }\end{array}$ & $\begin{array}{l}\text { - O seu mapa apresenta dados relevantes do seu } \\
\text { trabalho de campo? }\end{array}$ \\
\hline & $\begin{array}{l}\text { Dados- } \\
\text { Quantidade }\end{array}$ & $\begin{array}{l}\text { - Seu mapa mostra dados suficientes para o seu } \\
\text { estudo? }\end{array}$ \\
\hline & \begin{tabular}{|l|} 
Dados- \\
Estrutura \\
\end{tabular} & $\begin{array}{l}\text { - A estrutura de seu mapa permite encontrar dados } \\
\text { específicos rapidamente? }\end{array}$ \\
\hline \multirow[t]{3}{*}{ Mapa de escrita } & \begin{tabular}{|l|} 
Escrita- \\
Estrutura
\end{tabular} & $\begin{array}{l}\text { - O seu mapa apresenta uma estrutura clara para } \\
\text { você escrever sobre sua pesquisa? }\end{array}$ \\
\hline & $\begin{array}{l}\text { Escrita- } \\
\text { Conexões }\end{array}$ & $\begin{array}{l}\text { - Você mapeia as principais categorias de conexão, } \\
\text { como contexto, hipótese, objetivos, experiências, } \\
\text { metodologia, descobertas e considerações? }\end{array}$ \\
\hline & $\begin{array}{l}\text { Escrita- } \\
\text { Compreensão }\end{array}$ & - Seu mapa ajuda você a entender o tema? \\
\hline
\end{tabular}

Fonte: Okada, 2010.

As características estéticas (Quadro 4) permitem que as equipes avaliem quando o mapa de investigação apresenta um design claro e significativo.

QUADRO 4 - Análise das características estéticas dos mapas de consulta

\begin{tabular}{|l|l|}
\hline Rubrica & Algumas perguntas para avaliar as características estéticas dos mapas \\
\hline Estrutura & $\begin{array}{l}\text { O título do mapa é visível e claro? } \\
\text { Os componentes e suas conexões estão bem organizados? }\end{array}$ \\
\hline
\end{tabular}




\begin{tabular}{|l|l|}
\hline & $\begin{array}{l}\text { As relações entre os objetos são bem descritas? } \\
\text { É fácil entender o mapa? }\end{array}$ \\
\hline Conteúdo & $\begin{array}{l}\text { O mapa oferece uma imagem global do seu conteúdo? } \\
\text { Os componentes são relevantes e claros? } \\
\text { O mapa alcança seu objetivo? } \\
\text { O mapa permite que você entenda seu conteúdo? }\end{array}$ \\
\hline Layout & $\begin{array}{l}\text { O design do mapa é claro? } \\
\text { O texto e as imagens estão bem organizados no mapa? } \\
\text { As conexões são visíveis e fáceis de serem identificadas? } \\
\text { O mapa permite que você leia e navegue facilmente em seu su } \\
\text { conteúdo? }\end{array}$ \\
\hline
\end{tabular}

Fonte: Okada, 2010.

Esses três conjuntos de critérios de avaliação foram usados para selecionar os melhores exemplos que representam cada um dos seis tipos de mapas de investigação.

\section{RESULTADOS}

\section{Problematização com mapas de pesquisa}

Em termos de cooperação (RQ1), a figura 4 fornece um "mapa de pesquisa" criado por estudantes-pesquisadores, do ensino médio, que usaram a abordagem de Escolarização Aberta. Participaram da pesquisa 30 estudantes, dois professores de ciências e um engenheiro de carros elétricos. O mapa de pesquisa sobre carros elétricos indicou a pergunta inicial dos estudantes, apoiada por seu professor de ciências: "O carro elétrico é a melhor opção de transporte para reduzir as emissões de CO2?".

Eles usaram um modelo do programa Power Point para organizar os principais componentes de seu estudo sobre carros elétricos, por exemplo, com a elaboração de um dilema (questão sociocientíficas), coleta de dados móveis, discussão de dados e elaboração de relatórios com mapa de dados, fotos e mapas de diálogo. Os estudantes interagiram com um engenheiro, para surgir novas perguntas, como por exemplo: "Quais são as vantagens e desvantagens dos carros elétricos para as pessoas que vivem em Milton Keynes? O que os pais dos alunos de nossa escola pensam sobre carros elétricos?". Os estudantes também discutiram com um pesquisador científico sobre suas hipóteses com base nos dados encontrados na Web: "Se o carro elétrico é carregado com eletricidade de fontes renováveis, as 
emissões do ciclo de vida do carro elétrico são praticamente nulas". Os estudantes também conversaram com suas famílias. Alguns estudantes tinham parentes que eram proprietários de carros elétricos.

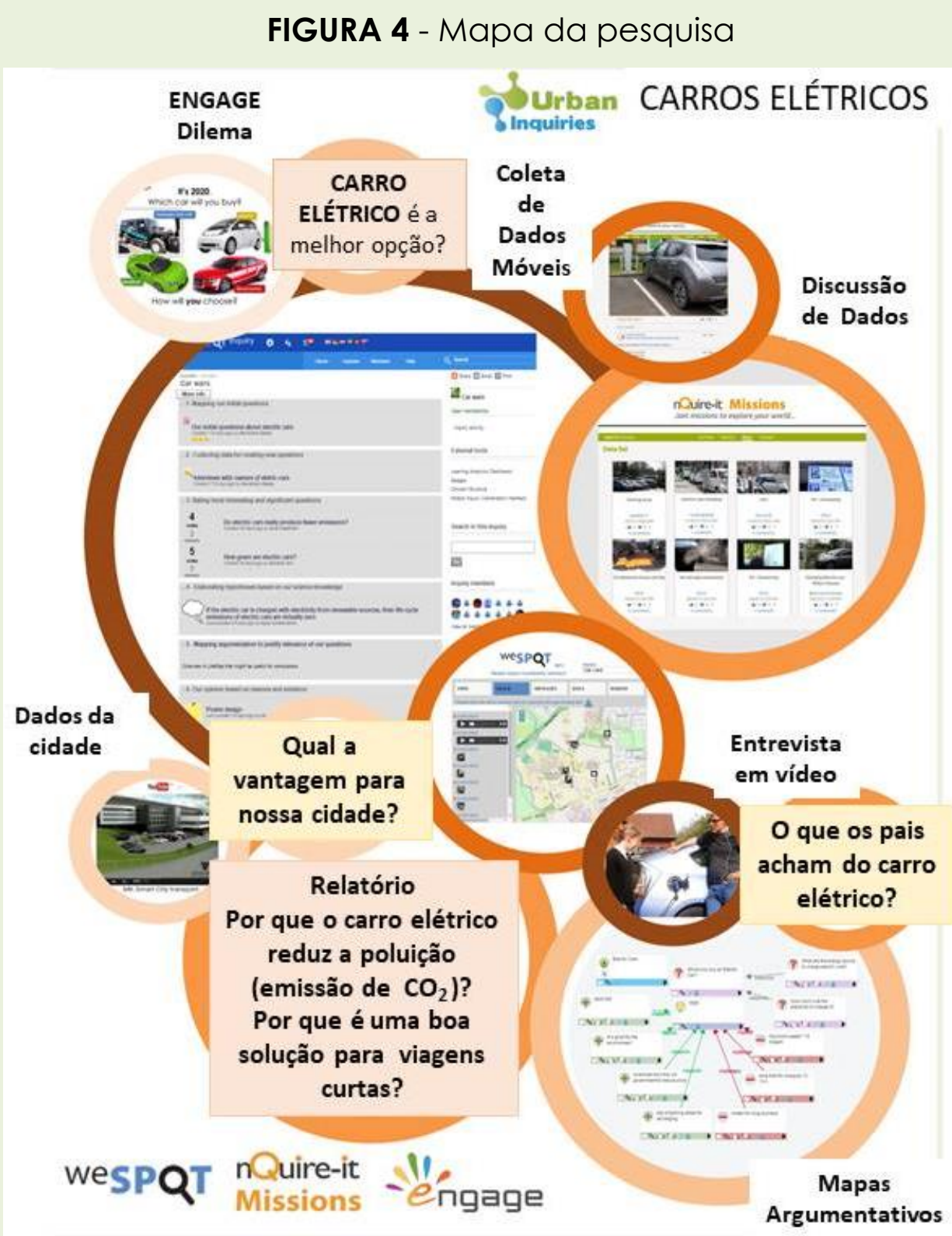

Fonte: ENGAGE Open Schooling - Mapa de pesquisa sobre carros elétricos (UK).

Autor: Alunos da escola secundária de Stantonbury

Participantes e funções: 30 alunos (líder do projeto), 2 professores de ciências (facilitador), 1 instrutor de TI (facilitador), 1 engenheiro de carros elétricos (mentor).

Objetivo Formal de Aprendizagem: Aplicar conhecimentos sobre dióxido de carbono atmosférico e avaliar soluções para o problema de aumentar as emissões de dióxido de carbono dos carros e justificar opiniões.

Diversão Profunda: jogo de guerra de carros, entrevistas na vida real, estudantesapresentadores em uma conferência. 
O pensamento em rede suportou 6 habilidades: elaborar perguntas, interrogar fontes, analisar dados, tirar conclusões, justificar opiniões e comunicar ideias.

Ferramentas usadas: WeSPOT (entrevista do engenheiro de coleta de dados de áudio), NQuire-it (coleta de dados de fotos com membros da comunidade e da família), ENGAGE (atividade de ensino aberto), LiteMap (mapa de escrita) Power Point (mapa de pesquisa), Word (publicação no blog).

A interação com a sua própria comunidade foi importante para que compartilhassem informações com seus pares e, gerando novas perguntas, como por exemplo: "Os carros elétricos produzem menos emissões?", "Quão verde são os carros elétricos? "; "Você compraria um carro elétrico? ". O mapa de argumentos criado no LiteMap, apoiado por um instrutor de TI (Tecnologia da Informação), ajudou os estudantes a conectar perguntas, afirmações, pró-argumentos, contra-argumentos e dados. Os estudantes usaram o mapa para escrever seu relatório de blog sobre "Electric cars save pollution. They are good for short drives", que foi compartilhado com suas famílias e com o engenheiro que os apoiou como mentor.

Em termos de pensamento em rede (RQ2), esse exemplo tem revelado que bons projetos de pesquisa dependem de questões significativas. No início de uma pesquisa, não é fácil definir uma questão relevante. Inicialmente, os estudantes-pesquisadores podem se perder quando precisam enfrentar muitas informações sem perguntas, ou quando há muitas perguntas, mas sem nenhuma referência significativa (OKADA, 2008). O mapeamento como ponto de partida - em um projeto de pesquisa com parceiros relevantes - ajuda os estudantes a encontrarem as melhores perguntas.

\section{Mapa de Referência - Organizando recursos}

A Figura 5 apresenta um pôster, de um mapa de referência criado por um educador científico, que contém vários tipos de recursos e contribuições de parceiros fornecidos na Europa para que estudantes com as suas comunidades no Brasil desenvolvam projetos de Escolarização Aberta, usando mapas de investigação.

Em termos de cooperação (RQ1), os parceiros dos estudantes eram um biotecnólogo e um pesquisador biólogo ambiental. O cenário da 
Escolarização Aberta era sobre o ZIKA questionando "se os mosquitos Aedes aegypti devem ou não ser exterminados", inspirados pela empresa Oxitec.

Este mapa de investigação mostra quatro referências para os estudantes que foram organizados em três etapas: um jogo de alimentos na web de conhecimento científico para iniciar sua investigação; um conjunto de cartões com o ponto de vista dos atores sociais para que eles criem argumentos, um mapa de modelo de avaliação de riscos versus benefícios para analisar e resolver a questão sociocientíficas; e as opiniões dos estudantes, com o modelo de mapa baseado em evidências, para comunicar suas descobertas apoiadas por suas parcerias.

FIGURA 5 - Mapa de referência

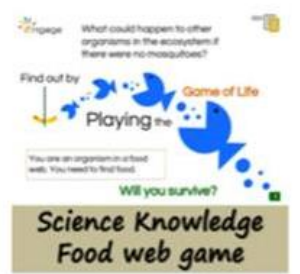

1. INVESTIGAR

Refletir um dilema e revisar as questões de pesquisa.
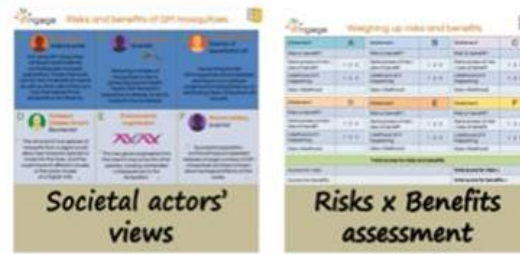

2. ANALISAR E RESOLVER

Elaborar questões, interrogar fontes, analisar dados, estimar riscos examinar consequências, usar a ética e tirar conclusões.

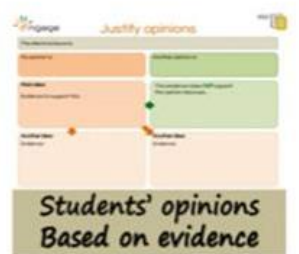

3. COMUNICAR

Criticar afirmações e comunicar ideias, justificando opiniões baseadas em evidência.

Por que e como os estudantes deveriam interagir com cientistas, companhias e comunidade?

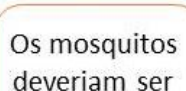
deveriam ser exterminados?
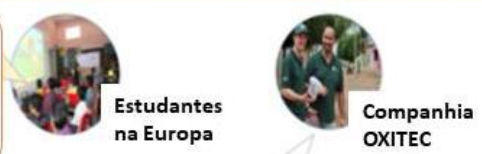

Mosquito

Transgênico produzido na OXITEC é a melhor solução?

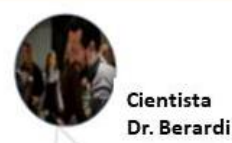

Que tal usar o Mesocyclops que é um microrganismo que come a lava do mosquito?

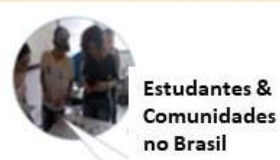

Qual a melhor alternativa para reduzir a ZIKA no Brasil?

Fonte: ENGAGE Open Schooling - Mapa de referência sobre ZIKA.

Autor: Open University - ENGAGE project coordinator.

Participantes e funçōes: 200 alunos (líder do projeto), 10 professores multidisciplinares (facilitador), 1 biotecnólogo, 3 pesquisadores acadêmicos, 1 biólogo pesquisador ambiental (mentor).

Objetivo formal de aprendizado: Interdependência - descreva como a população de uma espécie muda à medida que a população de predadores ou presas muda.

Diversão Profunda: Jogo ecossistema, debate com cientista, ação científica contra ZIKA.

O pensamento em rede apoiou 6 habilidades: Interrogar fontes, estimar riscos, usar a ética, justificar opiniões e comunicar ideias.

Ferramentas utilizadas: ENGAGE (atividade de ensino aberto), Power Point (ResearchMap), Word (Benefícios de risco - Mapa de referência), Notas para telefones móveis (Coleta de dados sobre as opiniões dos atores sociais). 
A pergunta do mapa de referência ilustrou porque e como os estudantes devem interagir com cientistas, empresas e comunidades. Os estudantes da Europa estavam interessados em saber como "os mosquitos deveriam ser exterminados"? A cooperação foi estabelecida com base no interesse comum. A empresa Oxitec apresentou um vídeo mostrando como o mosquito GM (Geneticamente Modificado) era usado como uma "solução de controle de vetores". O cientista ambiental apresentou uma proposta diferente - denominada com um microrganismo chamado "mesocyclops". Os estudantes no Brasil discutiram qual era a melhor solução para reduzir o ZIKA no Brasil? Apoiado pelas informações e cientistas da Europa.

Em termos de pensamento em rede (RQ2), o mapeamento de referências na Web pode ajudar os estudantes a procurar informações significativas, interrogar fontes, elaborar perguntas, por exemplo: Quais são as principais fontes? Quais são as principais teorias, fundamentos, conceitos e origens? Quais são os principais artigos, papers e outras referências? Quais são os principais estudos de caso? Existe algum exemplo prático? Quem são os contatos especializados que podem fornecer feedback? Quais são os principais debates sobre o tema? (OKADA, 2010).

\section{Mapa de Leitura - Interpretando e analisando textos}

A Figura 6 apresenta um mapa de leitura de uma discussão entre vários participantes interessados no desenvolvimento profissional de professores de ciências sobre 0 ensino de ciências com base em investigação - Inquiry-Based Science Education - IBSE.

Em termos de cooperação (RQ1), os participantes foram estudantes de doutorado, educadores de ciências, desenvolvedores de projetos STEM, designers de currículo e acadêmicos especializados em biotecnologia, meio ambiente e desenvolvimento sustentável. O mapa foi criado em colaboração com os facilitadores usando a ferramenta de anotação LiteMap. Os ícones foram adicionados no texto usando a ferramenta LiteMap BookMarklet no navegador, para quando ativado em seu próprio 
equipamento, qualquer parceiro pudesse ver os ícones adicionados por seus colegas. Os ícones ajudaram os leitores a identificar componentes e linhas de raciocínio, conectando perguntas, afirmações, argumentos a favor e contra-argumentos, bem como evidências (dados) para apoiar os argumentos. Também, permitindo que os estudantes identificassem as áreas que não foram mapeadas.

FIGURA 6 - Mapa de Leitura

$$
\begin{aligned}
& \leftarrow \rightarrow C \text { ก } \square \text { file:///C:/Users/Antony/Desktop/ale/GROUP\%20DISCUSSIONS.htm }
\end{aligned}
$$

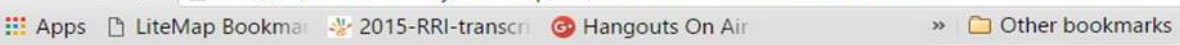

$$
\begin{aligned}
& \text { - } \Delta \text { Um tema relevante apresentado ? Como nós integramos desenvolvimento profissional, } \\
& \text { (E) aprendizagem baseada em investigação e dimensões éticas no ensino de ciências? } \\
& \text { ? As dimensões éticas e valores na educação-parte da preparação dos professores e o que } \\
& \text { as crianças fazem na escola... Por exemplo, th dilemas éticos na biotecnologia, problemas } \\
& \text { ambientais, desenvolvimento sustentável.. E Educação é mais do que simplesmente focar } \\
& \text { em completar as necessidades de conteúdos que nós temos hoje. Temos vários desafios. - } \\
& \text { incluindo a dificuldade de como nós ensinamos questões éticas na escola ...Preparar } \\
& \text { professores confidentes com conhecimento e habilidadesé essencial. }
\end{aligned}
$$

Fonte: ENGAGE Open Schooling - Reading Map para interpretar e analisar textos.

Autor: Equipe do seminário ENGAGE.

Participantes e funções: 6 professores de educação científica, 2 desenvolvedores de currículo, 3 especialistas acadêmicos, 1 coordenador de projeto, 3 pesquisadores acadêmicos (facilitador).

Objetivo Formal de aprendizagem: estabelecer um mapa da agenda de pesquisa

Diversão Profunda: debate, transcrição digital, anotação colaborativa, leitura e escrita com diversão.

O pensamento em rede suportou 6 habilidades: elaborar perguntas, interrogar fontes, usar ética, justificar opiniões e comunicar ideias.

Ferramentas utilizadas: ENGAGE (atividades de ensino aberto), ferramenta LiteMap Annotation.

O mapa mostra uma pergunta de um professor de ciências: "Como podemos integrar o desenvolvimento profissional dos professores, o IBSE e as dimensões éticas no ensino de ciências?". Uma reivindicação foi vinculada à pergunta de um educador de professores de ciências: "Os valores e dimensões éticas na educação fazem parte de nossa preparação dos professores e o que as crianças fazem (atividades) na sala de aula". Um contra-argumento, adicionado por um pesquisador acadêmico, indicou que "não é uma resposta fácil, porque trabalhar com ética envolve valores e 
experiências pessoais e os professores recebem mensagens confusas". A captura de tela do mapa de leitura apresentou três perguntas, três afirmações, três argumentos a favor e três contra-argumentos de diferentes participantes.

Em termos de pensamento em rede (RQ2), o mapa de leitura ajudou os pesquisadores a resumir o documento e, também, examinar, analisar e revisar o conteúdo visualizando, reconectando os ícones de diferentes perspectivas usando a tela LiteMap.

Para anotar o mapa, os participantes tiveram que selecionar sentenças relevantes e interpretá-las no contexto, atribuindo um ícone, que fornecia algumas informações extras sobre a discussão. Os ícones com conteúdo anotado foram capturados automaticamente no LiteMap e permitiram aos participantes recombinar e reconectar a anotação para criar novas linhas de raciocínio. A interpretação implicava em apreender significados, dividindo o texto complexo em partes simples. O mapeamento de declarações importantes de um documento e suas inter-relações usando ícones forneceu algumas dicas para os leitores interpretarem o conteúdo. Através da leitura de mapas, os participantes visualizam o que é importante, para armazenar e recuperar rapidamente informações.

\section{Mapa de Teoria - Compreendendo conceitos}

A Figura 7 apresenta um mapa de teoria incluindo três perspectivas: contexto (amarelo), conceitos-chave e descrição (azul). Este mapa conceitual criado no CMap Tools e discutido no Google Hangouts focou o tópico "Mídia, Educação, Trabalho e Sociedade".

Em termos de cooperação (RQ1), o mapa foi criado por um professor acadêmico, no Brasil, para discutir um projeto de pesquisa de pós-doutorado com o feedback de oito participantes de diferentes áreas. O mapa começou com uma pergunta sobre "Quais são as principais competênciaschave na Educação para ajudar os alunos a se tornarem participantes sócio-produtivos ativos na sociedade" Em termos de conteúdo, quatro áreas 
(em amarelo) foram conectadas: (1) Desenvolvimento profissional; (2) Tecnologia e inclusão social; (3) Ensino superior; e (4) Gerenciamento. Alguns conceitos-chave também foram apresentados no mapa com conexões para fornecer mais detalhes, por exemplo: produção de conhecimento, competências do século 21 , educação profissional e metodologia científica.

FIGURE 7 - Mapa de Teoria

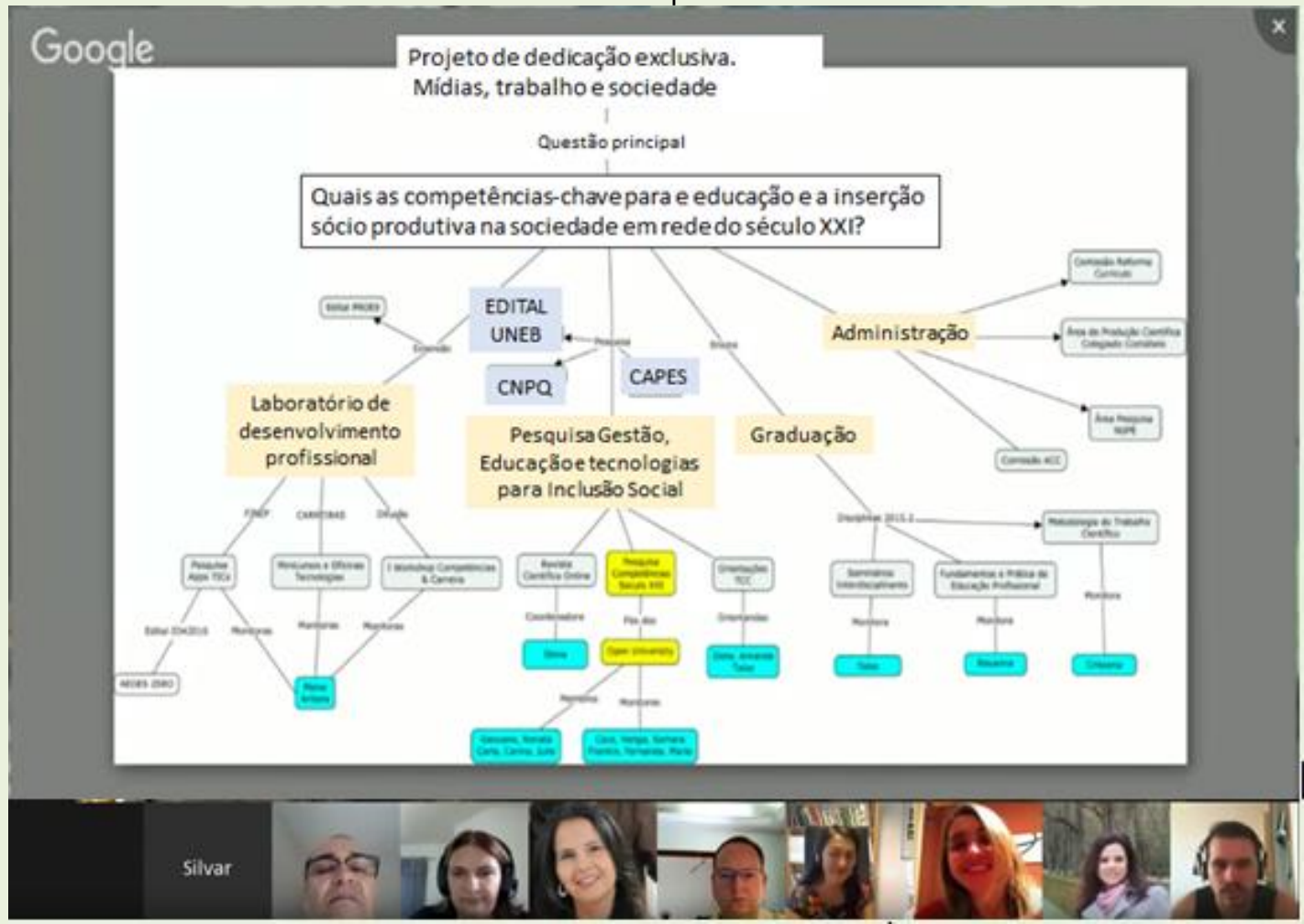

Fonte: ENGAGE Open Schooling - Mapa teórico sobre competências e empregabilidade Autor: Professor acadêmico do Brasil COLEARN COMMUNITY.

Participantes e funções: 5 educadores multidisciplinares, 3 pesquisadores acadêmicos, 1 educador de biologia científica, 1 conselheiro de Políticas Científicas.

Objetivo Formal de Aprendizagem: Revisão por pares de uma proposta de pós-doutorado Diversão Profunda: Mapa Visual, Diálogo Online, Revisão de Pares Colaborativa.

O pensamento em rede suportou 6 habilidades: elaborar perguntas, interrogar a fonte, justificar opiniões e comunicar ideias.

Ferramentas usadas: ENGAGE (atividade escolar aberta), CMap Tools e Google Hangout.

Em termos de pensamento em rede (RQ2), o mapa da teoria permitiu ao professor-pesquisador e aos parceiros visualizar e discutir a conexão entre conteúdo, conceito e sua descrição. Esclarecer conceitos foi um passo importante para entender as teorias e receber feedback significativo.

Por meio de conceitos bem mapeados, especialistas e membros da comunidade puderam visualizar os componentes relevantes e suas 
conexões, comparar, combinar, comentar e sugerir novas referências. O mapeamento de teorias foi um bom exercício para refletir sobre princípios importantes para sustentar um projeto de pesquisa.

\section{Mapa de trabalho de campo - Coleta e análise de dados sobre o trabalho de campo}

A Figura 8 fornece um mapa do trabalho de campo que contém vários outros mapas não digitais, desenvolvidos por uma escola de educação profissional com professores de várias áreas: administração agrícola, análises clínica, comércio, enfermagem, meio ambiente, nutrição, publicidade e segurança no trabalho. Os mapas em papel foram digitalizados usando telefone móvel e carregados (por upload) no LiteMap.

Em termos de cooperação (RQ1), os estudantes tinham entre 18 e 22 anos de idade, em Irecê (BA), uma cidade amplamente afetada pelo ZIKA vírus. A maioria dos estudantes é de famílias de baixa renda e não possui acesso a computadores. Eles criaram seus mapas não digitais, que foram organizados e analisados em um mapa do trabalho de campo como parte dos dados da pesquisa. Os especialistas conseguiram ver o conteúdo, fazer comentários e fornecer feedbacks, que foram apresentados pelo corpo docente aos estudantes usando dispositivos móveis.

FIGURA 8 - Mapa de trabalho de campo

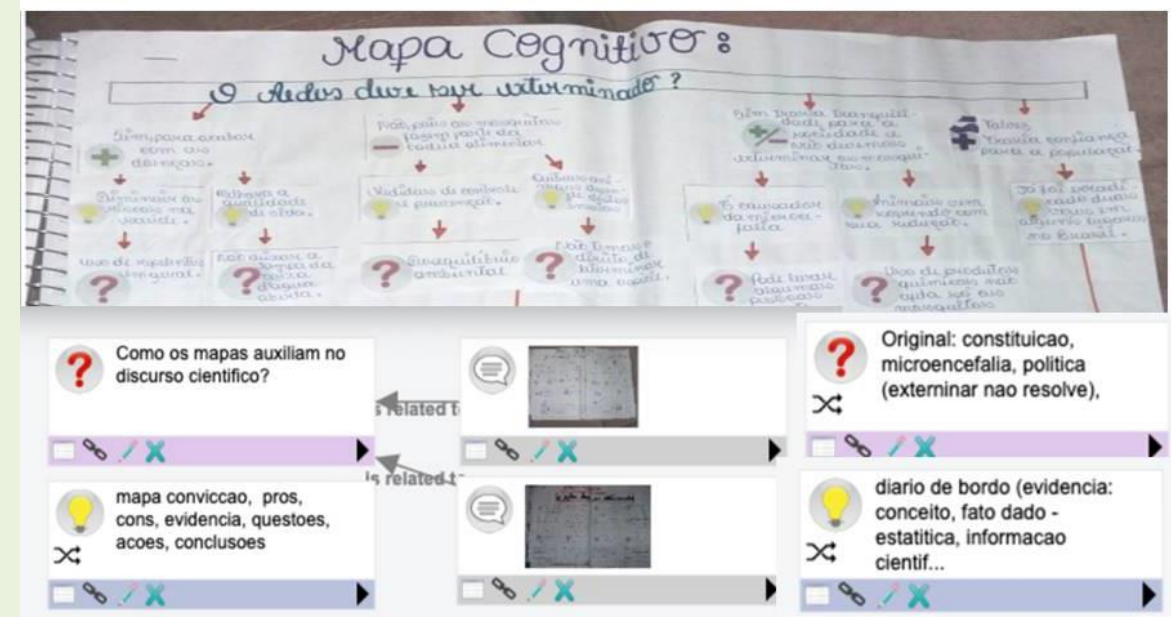

Fonte: ENGAGE Open Schooling - Mapa de Referência sobre ZIKA

Autor: CETEP - Escola Profissional (Brasil)

Participantes e funções: 200 estudantes (líder do projeto), 10 professores multidisciplinares (facilitador), 3 pesquisadores acadêmicos, 1 pesquisador biólogo ambiental (mentor). 
Objetivo formal de aprendizado: - descreva como a população de uma espécie muda à medida que a população de predadores ou presas muda

Diversão Profunda: Jogo Interdependência, Mapa de diálogo com base em evidência e inclusão digital.

O pensamento em rede apoiou 6 habilidades: Interrogar fontes, estimar riscos, usar ética, justificar opiniões e comunicar ideias.

Ferramentas utilizadas: ENGAGE (atividade de ensino aberto), Power Point (Research Map), Word (Benefícios de Risco - Mapa de Referência), Notas para Celular (Coleta de dados sobre a visão dos atores sociais).

Em termos de pensamento em rede (RQ2), o mapa do trabalho de campo ajudou os participantes a organizar um grupo de dados (mapas e recursos) e navegar por toda a amostra. Cada pesquisador educacional deste projeto conseguiu criar seu mapa de trabalho de campo e adicionar os mesmos componentes em sua própria tela. Eles foram capazes de navegar pelos mapas que continham os mesmos dados, mas analisando com base em perguntas de pesquisa diferentes e usando conjuntos de componentes diferentes. Eles também foram capazes de fazer conexões entre os diferentes mapas, realizando interpretações do trabalho de campo. Ademais, visualizar e analisar dados importantes por meio de mapas permitiu que os participantes reorganizassem e conectassem múltiplas visualizações e obtivessem uma visão geral das descobertas mais relevantes.

\section{Mapa de escrita - Sistematizando a pesquisa}

A Figura 9 apresenta um relatório desenvolvido por um grupo de equipe de pesquisa e inovação do Brasil e do Reino Unido. O mapa de escrita incluía uma anotação em vídeo, em que indicava os principais benefícios e desafios do uso de realidade mista, com Microsoft Hololens, para ensinar os componentes e as funcionalidades de um motor elétrico. $O$ mapa de escrita apoiou a elaboração de um artigo científico publicado em uma edição científica revisada por pares da Computer Science.

Em termos de cooperação (RQ1), o mapa de escrita resumiu o estudo de pesquisa e a discussão dos resultados sob a distinta perspectiva dos participantes: estudantes e parceiros envolvidos no projeto. Esses participantes formavam um grupo de 25 estudantes de engenharia mecânica, 2 facilitadores, o líder da equipe do curso, um profissional de 
Ciência da Computação, um professor de Engenharia Mecânica e um educador sênior de pesquisa STEM.

O mapa de escrita apresentava os pontos de vista distintos dos participantes ligados ao vídeo. Tudo começou com a introdução de uma pergunta-chave: "Qual é o futuro da educação para o desenvolvimento do profissional do futuro?". O chefe da Instituição acrescentou um comentário: "Hololens é uma inovação tecnológica para ajudar os alunos a explorar cenários inconcebiveis sem esse recurso". A equipe do curso mencionou que "Estratégias pedagógicas, como cenários situados, permitem aos estudantes aplicar conhecimentos e habilidades para resolver problemas apoiados por colegas e especialistas usando o Hololens". Vários benefícios foram apresentados (ajuda para os estudantes explorar dados visuais; os estudantes podem refletir sobre informações abstratas). Também, foram incluídos alguns desafios (requer que os professores mudem a sua lição; a tecnologia é muito cara).

FIGURA 9 - Mapa de escrita

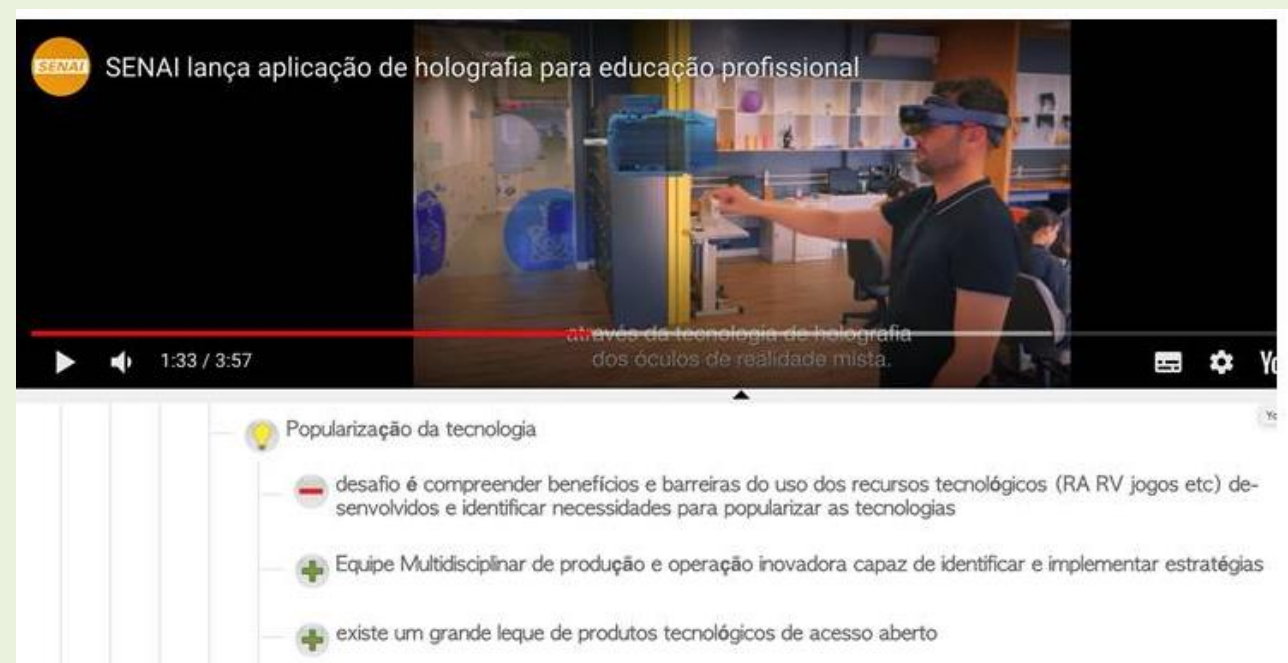

Fonte: ENGAGE Open Schooling - Futuro da Educação para o desenvolvimento do profissional do futuro.

Autor: SENAI Brasil e Open University UK.

Participantes e funções: 200 alunos (líder do projeto), 10 professores multidisciplinares (facilitador), 3 pesquisadores acadêmicos, 1 pesquisador biólogo ambiental (mentor).

Objetivo formal de aprendizagem: desenvolver um relatório científico e um trabalho.

Diversão Profunda: Mapa de Anotação de Vídeo, Escrita multimidiática.

O pensamento em rede apoiou 6 habilidades: Interrogar fontes, estimar riscos, usar ética, justificar opiniões e comunicar ideias.

Ferramentas usadas: LiteMap, YouTube Video Clip. 
Em termos de pensamento em rede (RQ2), pesquisadores e estudantes foram capazes de descrever e visualizar os principais componentes da argumentação e suas conexões. O mapa de escrita forneceu um resumo dos principais elementos focando nas principais questões. Os participantes integraram todas as evidências, incluindo argumentos que justificam a conclusão. Através do mapa de escrita, não apenas os resultados foram visualizados, mas também foi evidenciado como foram encontrados e como o problema da pesquisa foi respondido. O artigo estruturado foi útil para apresentar o estudo e as descobertas, incluindo os resultados e a conclusão da pesquisa.

\section{DISCUSSÕES E RECOMENDAÇÕES}

A principal pretensão deste estudo é mostrar que a criação de mapas de investigação ajuda os estudantes a tornarem explícitos seus pensamentos, bem interconectados. A pesquisa apoia os estudantes, professores e parceiros no processo metacognitivo de desenvolver estratégias de melhor pensamento de forma colaborativa. As vias de consulta representadas pelos mapas de consulta fornecem representações gráficas aos estudantes para refletir em ação e refletir sobre suas próprias reflexões durante seus projetos de pesquisa (OKADA, 2010).

Analisar componentes e os dados de pesquisa durante um estudo empírico exige uma reflexão profunda e sistemática de Whyte (1991). Mapas de investigação bem projetados podem facilitar 0 processo de análise visualmente; principalmente quando todos os componentes importantes são conectados de maneira bem estruturada e coerente.

Os resultados deste estudo indicam que 0 mapeamento de investigação é um método útil para a Escolarização Aberta, bem como para o estudante desenvolver o pensamento em rede e a cooperação entre parceiros; o que é significativo para aprimorar a educação em rede. Por meio de um conjunto de exemplos de práticas recomendadas, o método de mapeamento de investigação fornece: 
- Um conjunto de princípios e ferramentas autorreflexivas para apoiar o pensamento em rede.

- Diferentes maneiras de aplicar mapas de investigação liderados por participantes distintos.

- Uma variedade de projetos de Escolarização Aberta com mapeamento de investigação.

- Maneiras significativas pelas quais a cooperação entre escola, comunidade universitária e indústria é implementada com mapas de perguntas para melhorar a Escolarização Aberta.

- Instrumentos e recursos interconectados para criar e reutilizar mapas em diferentes cenários.

Vários exemplos de mapas de investigação indicaram o envolvimento de estudantes e parceiros, com base no pensamento em rede, em colaboração e interconectado, apoiado por interesses comuns. O processo colaborativo de mapeamento de investigação ajuda os parceiros a projetar, refletir e moldar perguntas, referências, conceitos, fornecendo feedback sobre as principais habilidades de pensamento, através de interações na solução de problemas e construção coletiva de conhecimento (OKADA, 2005). Baker (2003) evidencia que a discussão colaborativa de solução de problemas e argumentação ajuda os estudantes a escolher melhores soluções de problemas e a coelaborar uma compreensão mais profunda. McTighe (1992, p. 190) também aponta que o uso de representações gráficas beneficia os estudantes de pelo menos quatro modos:

1. Proporciona um ponto focal para as discussões em grupo, oferecendo um quadro de referência comum para pensar.

2. Fornece uma "memória de grupo" ou produto tangível da discussão do grupo.

3. Incentiva os estudantes a expandir seu próprio pensamento, considerando diferentes pontos de vista.

4. Auxilia a articular diversas linhas de raciocínio e ajuda a tornar visível o processo invisível de pensamento para todos os participantes. 
Conforme indicado em estudos anteriores (OKADA; BUCKINGHAM SHUM; SHERBORNE, 2008; BUCKINGHAM SHUM; OKADA, 2014), alguns pesquisadores argumentam que mapas construídos por facilitadores ou parceiros podem ser difíceis de serem entendidos por outros estudantes (MAYER, 2003). As anotações representacionais nos mapas se manifestam também como restrições, apresentando limites à expressividade e à sequência na qual as unidades de conhecimento podem ser expressas (SUTHERS, 2003). Na perspectiva de Zimmer, "os mapas podem funcionar bem como uma ferramenta para fazer sentido, mas não necessariamente como uma ferramenta para transmitir conhecimento à outra pessoa" (OKADA; CONNOLLY, 2008, p. 12).

Existem diversos fatores envolvidos na criação de mapas bem projetados, tais como a experiência no domínio do aluno, a fluência com as ferramentas, a familiaridade com as técnicas de mapeamento e a maneira como as suas atividades são projetadas.

Fazer com que os alunos verifiquem criticamente as informações, uns dos outros, a fim de manter níveis compartilhados de entendimento, é útil e pode ser efetivamente provocado através do design de tarefas, características da interface e do modo de comunicação" (VEERMAN, 2003, p. 141).

Nesse contexto, se torna importante, fornecer aos estudantes padrões estruturais para melhor visualização da informação, maximizando a compreensão do conhecimento e o desempenho da pesquisa (CHEN; CZERWINSKI, 1997).

Conforme explicado, as representações gráficas são úteis para o desenvolvimento do ciclo de pesquisa, de acordo com os fundamentos de Llewellyn (2005). A representação do processo de pesquisa ainda pode ser vista como uma espiral, em uma perspectiva cíclica de pesquisa (BLAXTER; HUGHES; TIGHT, 2001). No entanto, de acordo com suas necessidades, o pesquisador escolherá executar todas as fases presentes na espiral ou apenas algumas etapas do processo, com base na intensidade das interações das comunidades conectadas à rede de pesquisa. 
Os estudantes de pesquisa também devem estar cientes de questões como: Para que serve este mapa? O que estou tentando realizar usando este mapa? O que este mapa mostra que eu quero descobrir? O que este mapa mostra que eu já sei? O que falta neste mapa que devo incluir para deixar claro? Há algo que eu possa mudar neste mapa para torná-lo mais útil? Em que outras situações e problemas esse mapa pode ser útil?

O Quadro 5 apresenta alguns benefícios do Mapeamento de Investigação para pesquisa colaborativa, que apoia este estudo atual, além de estudos anteriores (OKADA, 2006; OKADA, 2010, ROCHA; ROCHA; OKADA; 2018).

QUADRO 5 - Promoção de habilidades de pensamento em rede através de mapas de investigação

\begin{tabular}{|c|c|c|}
\hline $\begin{array}{c}\text { Mapa de } \\
\text { Investigação }\end{array}$ & $\begin{array}{l}\text { Habilidades de pensamento } \\
\text { em rede }\end{array}$ & $\begin{array}{c}\text { Benefícios do mapeamento de } \\
\text { investigação para projetos de } \\
\text { Escolarização Aberta }\end{array}$ \\
\hline $\begin{array}{l}\text { Mapa de } \\
\text { pesquisa }\end{array}$ & $\begin{array}{l}\text { Solução de problemas: } \\
\text { reformular questões, encontrar } \\
\text { novas alternativas, construir } \\
\text { aceitação } \\
\text { Design: formular metas, elaborar } \\
\text { resultados e revisar o processo. }\end{array}$ & $\begin{array}{l}\text { 1. Visualizar as principais ideias e } \\
\text { identificar as principais perguntas, } \\
\text { nas quais a maioria dos parceiros } \\
\text { está interessada. } \\
\text { 2. Encontrar um foco comum para a } \\
\text { pesquisa colaborativa. }\end{array}$ \\
\hline $\begin{array}{l}\text { Mapa de } \\
\text { referência }\end{array}$ & $\begin{array}{l}\text { Tomada de decisão: identifique } \\
\text { possibilidades, gere alternativas, } \\
\text { compare opções. }\end{array}$ & $\begin{array}{l}\text { 3. Identificar a literatura relevante } \\
\text { com recomendações colaborativas. } \\
\text { 4. Agrupar recursos para apoiar } \\
\text { projetos diferentes. }\end{array}$ \\
\hline Mapa de leitura & $\begin{array}{l}\text { Avaliação: defina critérios, } \\
\text { avalie informações, reconheça } \\
\text { os erros. }\end{array}$ & $\begin{array}{l}\text { 5. Anotar ideias de forma } \\
\text { colaborativa a partir de textos. } \\
\text { 6. Discutir significados dos principais } \\
\text { conceitos com o apoio dos } \\
\text { parceiros. }\end{array}$ \\
\hline Mapa de teoria & \begin{tabular}{lrr|} 
Conexão: & comparar & e \\
contrastar, inferir & dedutiva & e \\
indutivamente, & identificar \\
relacionamentos. & & \\
\end{tabular} & $\begin{array}{l}\text { 7. Visualizar conexões e caminhos. } \\
\text { 8. Reconstruir novos significados. }\end{array}$ \\
\hline $\begin{array}{l}\text { Mapa de } \\
\text { trabalho de } \\
\text { campo }\end{array}$ & 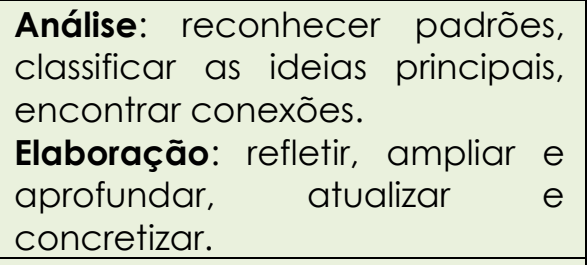 & $\begin{array}{l}\text { 9. Organizar um trabalho de campo } \\
\text { através de mapas. } \\
\text { 10. Classificar e categorizar os } \\
\text { dados. } \\
\text { 11. Identificar novas questões a } \\
\text { serem esclarecidas. }\end{array}$ \\
\hline Mapa de escrita & $\begin{array}{l}\text { Síntese: planeje, pressuponha, } \\
\text { resuma. } \\
\text { Imaginação: preveja, reflita, } \\
\text { visualize. }\end{array}$ & $\begin{array}{l}\text { 12. Integrar perguntas, ideias, } \\
\text { argumentos e evidências. } \\
\text { 13. Organizar uma estrutura clara } \\
\text { para apresentar o pensamento } \\
\text { colaborativo. }\end{array}$ \\
\hline
\end{tabular}

Fonte: Okada, 2010. 


\section{CONSIDERAÇÕES FINAIS}

Este estudo destaca o método de mapeamento de investigação como um método participativo para envolver vários parceiros na identificação de questões relevantes e criar cenários de problemas reais para promover projetos de Escolarização Aberta. Através de seis tipos de mapas de pesquisa, este estudo indica diferentes usos do mapeamento de investigação para desenvolver o pensamento em rede.

Os mapas de investigação, criados por pesquisadores, mostram que as representações gráficas são úteis para o desenvolvimento do ciclo de investigação (LLEWELLYN, 2005) e da espiral da pesquisa (BLAXTER; HUGHES; TIGHT, 2001). A abordagem de mapeamento de investigação pode ser usada para integrar um subconjunto ou até todos os seis tipos de mapas: Problematização, Revisão de Literatura, Interpretação, Estudos Conceituais, Análise e Síntese. Esses seis modelos de mapas de pesquisa aplicados a projetos de Escolarização Aberta mostram que o pensamento visual é útil para os estudantes-pesquisadores implementarem projetos de pesquisa apoiados por parceiros (Figura 2).

Este estudo destaca, ainda, o papel da educação em rede na era digital apoiada pelo pensamento em rede. Novos estudos serão úteis para examinar a correlação entre o pensamento em rede e a alfabetização em rede, que inclui mídia de conhecimento e análise sociocientíficas de redes. Neste estudo, os exemplos discutidos mostram que os estudantes em parceria devem estar preparados para entender criticamente a sociedade em rede e a educação em rede, compreendendo as mudanças e os desafios para fazer recomendações para moldar a pesquisa e a inovação de maneira responsável e em conjunto.

Os seis exemplos de projetos de Escolarização Aberta mostram diretrizes, modelos, estratégias e ferramentas úteis para projetar, implementar e avaliar práticas de Escolarização Aberta. Os exemplos fornecidos trazem: cenários, participantes, especialistas e profissionais, incluindo seu papel em atividades de aprendizagem, habilidades de investigação, benefícios e 
resultados. Nossas descobertas mostram diferentes maneiras pelas quais 0 mapa de investigação foi usado para promover a interação entre estudantes, professores, pesquisadores, profissionais das áreas científica e tecnológica, políticas públicas e engajamento da comunidade.

Os mapas de investigação podem ser considerados artefatos estratégicos e heurísticos para representar o que é importante, interpretando e reconstruindo significados, registrando e compartilhando novas estruturas de componentes e conexões. Todas essas habilidades são essenciais em conjunto com o pensamento em rede, o aprendizado em rede e a pesquisa em rede, sendo apoiados pela educação em rede.

\section{AGRADECIMENTOS}

Somos gratos à rede de pesquisadores RRI-Network, no Brasil, pela parceria e disponibilização de dados de mapas de investigação para projetos de Escolarização Aberta. Este artigo é sustentado por estudos anteriores, em particular pela pesquisa de Okada (2010) sobre mapas em ambientes de aprendizagem colaborativa.

\section{REFERÊNCIAS}

ARCHER, Lovise et al. "Science capital": A conceptual, methodological, and empirical argument for extending bourdieusian notions of capital beyond the arts. Journal of Research in Science Teaching, v. 52, n. 7, p. 922-948, 2015.

BAKER, M. Computer-mediated argumentative interactions for the co elaboration of scientific notions. In: ANDRIESSEN, J.; BAKER, M.; SUTHERS, S. (Eds.). Arguing to Learn: Confronting Cognitions in Computer-Supported Collaborative Learning environments. Netherlands: Kluwer Academic Publishers. 2003.

BLAXTER, L.; HUGHES, C.; TIGHT, M. How to Research, 2nd Edit. Buckingham: Open University Press. 2001.

BRYDON, D. Globalization and higher education: Working toward cognitive justice. In: Valences of Interdisciplinarity: Theory, Practice, Pedagogy, edited by Raphael Foshay, 97-120. Athabasca, AB: Athabasca University Press, 2011.

BUZAN, T. The Mind Map Book: Radiant Thinking - The Major Evolution in Human Thought. London: BBC Publications, 1993. 
BUCKINGHAM SHUM, S.; OKADA, A. Knowledge cartography for controversies: the Iraq debate. In: Knowledge Cartography. Springer, London, 2014. p. 293308.

CASTELLS, M. A sociedade em rede: volume 1. São Paulo: Paz e Terra, 2010.

CHEN, C.; CZERWINSKI, M.. Spatial ability and visual navigation: An empirical study. New Review of Hypermedia and Multimedia, v. 3, n. 1, p. 67-89, 1997.

CONKLIN, J. Dialogue mapping: Building shared understanding of wicked problems. John Wiley, 2005.

COOK, L. K.; MAYER, R. E. Teaching readers about the structure of scientific text. Journal of Educational Psychology, v. 80, n. 4, p. 448, 1988.

EC - EUROPEAN COMMISSION. HORIZON 2020 Work Programme 2014 - 2015: Science with and for Society. European Commission Decision C. 2015. Disponível em: <https://ec.europa.eu/programmes/horizon2020/en/h2020section/responsible-research-innovation>. Acesso em: 18 de outubro de 2019.

EDELSON, D. C. Learning-for-use: A framework for integrating content and process learning in the design of inquiry activities. Journal of Research in Science Teaching, v. 38, n. 3, p. 355-385, 2001.

FERGUSON, J. M. Networks, Globalization, and World Bank Education Strategies. New Proposals: Journal of Marxism and Interdisciplinary Inquiry, $v$. 10, n. 1, p. 5-15, 2019.

FREIRE, Paulo. Educação como prática da liberdade. Editora Paz e Terra, 1967.

GELDER, T. Argument mapping with reason! able. The American philosophical association newsletter on philosophy and computers, v. 2, n. 1, p. 85-90, 2002.

HMELO-SILVER, C. E.; DUNCAN, R. G.; CHINN, C. A. Scaffolding and achievement in problem-based and inquiry learning: a response to Kirschner, Sweller, and Clarck. Educational psychologist, v. 42, n. 2, p. 99-107, 2007.

HOLST, J. Globalization and the future of critical adult education. In: Global issues and adult education: Perspectives from Latin America, Southern Africa, and the United States, p. 41-52, 2006.

JONASSEN, D. H. Computers as mindtools for schools: Engaging critical thinking. Prentice hall, 2000. 
LLEWELLYN, D. Teaching high school science through inquiry: A case study approach. Corwin Press, 2005.

MAYER, R. E. Learning and instruction. Prentice Hall, 2003.

MC TIGHE, J. Graphic organizers: Collaborative links to better thinking.

Enhancing thinking through cooperative learning, p. 182-197, 1992.

NOVAK, J. D. Learning, creating, and using knowledge: Concept maps as facilitative tools in schools and corporations. Mahvah: Lawrence Erlbaum Associates, 1998.

OKADA, A. The collective building of knowledge in collaborative learning environments. In: Computer-supported collaborative learning in higher education. IGI Global, 2005. p. 70-99.

OKADA, A. Cartografia Investigativa: Interfaces epistemológicas comunicacionais para mapear conhecimento em projetos de pesquisa. Tese de Doutorado. Programa de Pós-Graduação em Educação: Currículo. Pontifícia Universidade Católica de São Paulo São Paulo, 2006.

OKADA, A. (ed.). Cartografia Cognitiva: Mapas de conhecimento para pesquisa, educação e ensino. CoLearn, 1 (1). Brasil: KCM. 2008.

OKADA, A. Eliciting Thinking Skills with Inquiry Maps in CLE. In: TORRES, P. L.; MARRIOTT, R.C.V. (org). Handbook of Research on Collaborative Learning Using Concept Mapping. IGI Global, 2010.

OKADA, A. Scaffolding school students' scientific argumentation in inquirybased learning with evidence maps. In: OKADA, A.; BUCKINGHAM SHUM, S. J.; SHERBORNE, T. (eds). Knowledge Cartography: Software Tools and Mapping Techniques. Advanced Information and Knowledge Processing. Springer, London, 2014.

OKADA, A. Deep fun for deeper learning. Proceedings of ASE International Conference January 2020 UK Readings. 2020.

OKADA, A.; BUCKINGHAM SHUM, S. SHERBORNE, T. Knowledge Cartography: Software tools and mapping techniques. Advanced Information and Knowledge Processing, 1. London, UK: Springer, 2008.

OKADA, A.; CONNOLLY, T. Designing open educational resources through knowledge maps to enhance meaningful learning. International Journal of Learning Technology, v. 15, n. 7, p. 209-220, 2008.

OKADA, A.; RODRIGUES, E. A educação aberta com ciência aberta e escolarização aberta para pesquisa e inovação responsáveis. In: TEIXEIRA, C.; 
SOUZA, M. V. Educação Fora da Caixa: tendências internacionais e perspectivas sobre a inovação na educação. (v. 4). São Paulo: Blucher, 2018.

OKADA, A.; SHERBORNE, T. Equipping the Next Generation for Responsible Research and Innovation with Open Educational Resources, Open Courses, Open Communities and Open Schooling: An Impact Case Study in Brazil. Journal of Interactive Media in Education, v. 1, n. 18, p. 1-15, 2018.

OKADA, A.; ZEILIGER, R. The building of knowledge through virtual maps in collaborative learning environments. In: EdMedia+ Innovate Learning.

Association for the Advancement of Computing in Education (AACE), 2003. p. 1625-1628.

RAMOS, A. L. M.; KORB, T.; OKADA, A. Immersive Analytics Through HoloSENAI MOTOR Mixed Reality App. In: Intelligent Computing-Proceedings of the Computing Conference. Springer, Cham, 2019. p. 1259-1268.

ROCHA, A. K. L. T.; ROCHA, A. B. L.T.; OKADA, A. Rubric to assess evidencebased dialogue of socio-scientific issues with LiteMap. In: Technology Enhanced Assessment: 20th International Conference, TEA 2017, Barcelona, Spain, October 5-6, 2017, Revised Selected Papers. Springer, 2018.

ROSA, L. Q. et al. Polo EaD como mídia do conhecimento na indústria 4.0. (2018). In: Congresso Internacional da ABED de Educação a Distância, Anais da ABED. Florianópolis - SC. 2018.

RYAN, C. Science Education for Responsible Citizenship. Report to The European Commission. 2015.

SOUZA, M. V. Mídias Digitais, Globalização, Redes e Cidadania no Brasil (2015). In: SOUZA, M. V.; Giglio, K. (Eds.). Mídias Digitais, Redes Sociais e Educação em Rede: Experiências na Pesquisa e Extensão Universitária. São Paulo: Blucher, 2015.

SUTHERS, D. D. Representational guidance for collaborative inquiry. In: Arguing to learn. Springer, Dordrecht, 2003. p. 27-46.

UNESCO. Educação para a cidadania global: preparando alunos para os desafios do século XXI. Brasília: Unesco, 2015.

VEERMAN, A. L. Constructive discussions through electronic dialogue. In: ANDRIESSEN, J.; BAKER, M.; SUTHERS, D.(Eds.). Arguing to learn. Springer, Dordrecht, 2003. p. 117-143.

WHYTE, W. F. Participatory action research. CA: Sage Publications. 1991. 
Recebido em: 29 de fevereiro de 2020 Aprovado em: 21 de julho de 2020 Publicado em: 30 de julho de 2020 